\title{
A atual (2019) contrarreforma da previdência social sob a égide do capital financeiro: análises críticas
}

\author{
The current (2019) social security counter-reform under the aegis of finance capital: critical \\ analysis
}
Patrícia Soraya Mustafa* Bruna Bueno**

\begin{abstract}
Resumo: Este trabalho propõe-se a analisar, através de um estudo teórico e documental, como o capital financeiro, no Brasil, sobretudo a partir da agenda ultraneoliberal iniciada pelo governo ilegítimo de Michel Temer, e continuada pelo atual, busca sua reprodução incessante pela via do desmonte da previdência pública. Para tanto, dedica-se primeiramente a uma breve análise crítica acerca da atual conjuntura político-econômica, em tempos de crise, apreendendo fenômenos globais inerentes ao capitalismo contemporâneo e os rebatimentos desses para os sistemas de proteção social, especialmente para os sistemas de previdência. Em seguida, adentra nos pormenores da atual contrarreforma da previdência social brasileira, aprovada e promulgada, que deu origem a Emenda Constitucional (EC) 103/2019, analisando as principais mudanças, evidenciando seus impactos para os trabalhadores, como também denunciando a falácia dos argumentos utilizados pelo atual governo a fim de convencer a população de que a 'reforma' se fazia necessária. Por fim, conclui-se que esta contrarreforma coloca dificuldades no acesso aos benefícios previdenciários para os (as) trabalhadores (as), além de rebaixar os seus valores, e reforça o compromisso do Estado capitalista brasileiro com a reprodução do capital, pela via da apropriação do fundo público.
\end{abstract}

Palavras-chave: capital financeiro; Estado; fundo público; contrarreforma da previdência social; ultraneoliberalismo.

Abstract: This paper aims to analyze, through a theoretical study, how financial capital in Brazil, especially from the ultra-liberal agenda initiated by Michel Temer's illegitimate government, and continued by the current one, seeks its incessant reproduction through the dismantling of social security. To this end, it first devotes itself to a brief critical analysis of the current political-economic conjuncture, in times of crisis, apprehending global phenomena inherent to contemporary capitalism and their rebounds to social protection systems, especially to social security systems. It then goes into the details of the current approved and promulgated Brazilian social security counter-reform, which gave rise to Constitutional Amendment (EC) 103/2019, analyzing the main changes, highlighting their impacts on workers, as well as denouncing the fallacy of the arguments used by the current government to convince the population that 'reform' was needed. Finally, it is concluded that this counter-reform poses difficulties in access to social security benefits for workers, as well as lowering their values. And it reinforces the commitment of the Brazilian capitalist state to the reproduction of capital, through the appropriation of the public fund.

Keywords: Financial capital; State; public fund; social security counter-reform; ultraneoliberalism

\footnotetext{
* Professora do departamento de Serviço Social, da Universidade Estadual Paulista - UNESP/ Franca. Doutorado em Serviço Social.Pós Doutorado pela Universidade Católica de Lisboa, 2014.

** Bacharela em Serviço Social pela Faculdade de Ciências Humanas e Sociais - UNESP/Câmpus de Franca (SP); Pesquisadora do Grupo de Estudos e Pesquisa em Políticas Sociais (GEPPS-FCHS).
} 


\section{Introdução}

Partindo da concepção de que o motor do capitalismo, hoje, é o capital financeiro e que, portanto, a acumulação ocorre mais sob os ditames da propriedade do que da produção, "[...] propriedade essa que é cada vez menos de meios de produção e cada vez mais de capital fictício [...]" (PAULANI, 2019, p. 51), este artigo se coloca a analisar como o capital financeiro, no Brasil, sobretudo a partir da agenda ultraneoliberal de Michel Temer e de Bolsonaro, busca sua reprodução incessante utilizando como um dos meios para isso a privatização dos sistemas de previdência social públicos.

Nesta direção, as privatizações constituem-se em uma das formas de valorização, na medida em que se retira do Estado alguns serviços e bens (diga-se de passagem, fundamentais para a garantia da soberania nacional), e passa-se para o mercado, a fim de gerar mais valor.

O controle exacerbado das finanças públicas também pode se converter em uma possibilidade de gerar mais valor. Neste sentido, medidas que possibilitem que o Estado "gaste" menos em alguns setores, sobretudo no campo dos direitos sociais, de acordo com o pensamento ortodoxo, também favorece o mercado duplamente: de um lado abrindo novos nichos de exploração, e de outro possibilitando a expropriação do fundo público. A Emenda Constitucional (EC) 95/2016 (BRASIL, 2016), promulgada no Brasil pós-golpe, possibilita esta pujança do capital.

Outra maneira de acumulação de riqueza financeira pode-se dar via destruição da previdência social pública, através da implementação de regimes de capitalização, muito rentáveis ao capital financeiro.

Neste artigo, através de um estudo teórico e documental evidenciaremos e analisaremos especificamente o projeto de contrarreforma ${ }^{1}$ da previdência social expresso no Projeto de Emenda Constitucional (PEC) 06/2019, hoje aprovado e promulgado, dando origem a Emenda Constitucional (EC) 103/2019 (BRASIL, 2019).

Para isso, primeiramente faremos uma breve análise acerca da atual conjuntura político-econômica, em tempos de crise, apreendendo fenômenos globais inerentes ao processo de restauração do capital, o neoliberalismo e a financeirização, e os impactos

\footnotetext{
${ }^{1}$ Utiliza-se contrarreforma aqui no sentido de Behring (2003).
} 
destes para os sistemas de proteção social, especialmente para os sistemas de previdência pública, denunciando os reais interesses do capital e do seu Estado pela mesma.

Logo em seguida adentraremos nos pormenores da EC 103/2019, elucidando as principais modificações que esta imputa ao sistema de previdência social, sobretudo ao Regime Geral de Previdência Social (RGPS), e os seus efeitos para a classe trabalhadora. Antes disso, desvelaremos os falsos argumentos utilizados pelo atual governo (2019) e pela mídia de plantão, a fim de convencer a sociedade, inclusive a classe trabalhadora, de que a reforma da previdência social se fazia necessária.

Assim, ao final, os leitores poderão concluir, juntamente com as autoras, a relação dialética que se impõe no Brasil, entre a ampliação do capital financeiro e o encolhimento da política social previdenciária, fruto de análise deste ensaio.

\section{A relação dialética entre a expansão do capital financeiro e o encolhimento da previdência social pública}

Desde o último quartel do século passado o modo de produção capitalista vem passando por profundas transformações políticas, econômicas e sociais, as quais redefiniram a dinâmica do capitalismo contemporâneo por completo. Destaca-se que, dentre essas mudanças, a principal refere-se à nova forma de "definir, gerir e realizar a riqueza no capitalismo" (BRAGA, 1997, p. 195), a financeirização, cujo traço mais emblemático remete à vigência de um padrão de acumulação exterior à esfera produtiva, que procura desenvolverse predominantemente por canais financeiros "[...] sob a forma de juros de empréstimos, de dividendos e outros pagamentos recebidos a título de posse de ações e, enfim, de lucros nascidos de especulação bem-sucedida". (CHESNAIS, 2005, p. 35).

De acordo com Chesnais (2015, p. 9), com as finanças tem-se "[...] dinheiro produzindo dinheiro, um valor valorizando-se por si mesmo, sem que nenhum processo (de produção) sirva de mediação aos dois extremos [...]", o que também significa a primazia da especulação e dos imperativos financeiros em detrimento dos investimentos e dos interesses da produção; crescimento da desigualdade e endividamento das famílias em função dos ganhos financeiros das elites; e penetração das finanças em todas as dimensões da reprodução social, influenciando e orientando políticas públicas em outras latitudes, remercantilizando o que havia sido desmercantilizado, substituindo a provisão pública por 
uma gama de seguros incapazes de cobrir os riscos que se propõe. (LAVINAS; ARAÚJO \& BRUNO, 2017).

Ressalta-se que há uma relação imbricada entre financeirização e neoliberalização, de modo que a transformação sistêmica das economias maduras capitalistas é inerente à própria lógica desse ideário, cuja natureza só pode ser compreendida se contextualizada no seio das relações sociais e dos conflitos inerentes entre capital e trabalho. Definido por Harvey (2012, p. 27) como um "[...] projeto político de restabelecimento das condições de acumulação do capital e de restauração do poder das elites econômicas [...]", o neoliberalismo ascende-se a partir do início dos anos de 1980, após a crise global dos anos setenta, redefinindo o papel do Estado nas relações econômicas e sociais, suscitando, dentre outras medidas, processos de privatizações e ondas de desregulamentação e liberalização financeira, destruindo as regulamentações e restrições sociopolíticas impostas ao movimento do capital e restaurando privilégios das elites econômicas, significativamente limitados após a crise de 1929 e, principalmente, após a II Guerra Mundial, quando se firmara o "compromisso keynesiano ou social democrata" (DUMÉNIL \& LÉVY, 2007) como resultado das lutas dos trabalhadores.

Como elucida Netto (2012), a desqualificação do Estado tem sido "a pedra de toque" do neoliberalismo, que promove o discurso de que a intervenção estatal nas relações econômicas e sociais é um peso a ser anulado em prol do crescimento econômico e superação da crise. Tal desqualificação, todavia, é perpassada por interesses políticos bastante específicos da burguesia e deve ser observada à luz da ofensiva do capital, em tempos de crise, contra a classe trabalhadora. (CARAMURU, 2018a). Além do mais, é válido considerar que, para além de um instrumento de regulação, "[...] o Estado é um fenômeno especificamente capitalista [...] elemento necessário para completude da própria reprodução do capital" (MASCARO, 2013, p. 18-30), cuja forma política é atravessada, necessariamente, por uma série de contradições, conflitos, arranjos e lutas de classe, erigindo-se a partir das formas sociais do capitalismo.

Disso depreende-se que, a partir da adoção de novas configurações de poder pelo sistema do capital na contemporaneidade, o Estado capitalista, emoldurando-se em consonância com as demandas da forma-mercadoria, converte-se "[...] numa instância institucional organizadora dos espaços econômicos necessários ao desenvolvimento da 
acumulação rentista" (BRUNO \& CAFFE, 2017, p. 1028), priorizando os interesses da alta finança em detrimento das necessidades sociais e do desenvolvimento nacional, desenhando suas políticas econômicas e sociais de acordo com as aspirações do mercado financeiro. (BUENO \& MUSTAFA, 2019). Não é por menos que Chesnais (2005; 2015) afirma, veementemente, que os fundamentos da atual mundialização financeira são tanto econômicos como políticos, repudiando a vulgata neoliberal segundo a qual o Estado é "exterior" ao "mercado". Longe de ser fruto de um desenvolvimento natural, o triunfo das finanças não poderia ser feito sem as inúmeras e repetidas intervenções das instâncias políticas, sobretudo dos países mais poderosos como os Estados Unidos.

Nesse contexto, o capital, orquestrado pelo capital portador de juros, reproduzindo seus vínculos institucionais com o Estado, encontra nas contrarreformas das políticas sociais o mecanismo por meio dos quais se constituem os novos nichos de acumulação, recolocando-as sobre patamares e perspectivas cada vez mais distantes da experiência social-democrata europeia. Conforme assinala Boschetti (2012), de "motores" do crescimento, as políticas sociais passam a ser consideradas como "freios" do crescimento econômico e sucedem-se as críticas dos liberais-conservadores, argumentando que foram os "gastos generosos" dos Estados de Bem-Estar que causaram os déficits fiscais dos países que o adotaram e são estes gastos que impedem a superação da crise, perturbando a saudável economia de mercado.

A partir disso, legitima-se um conjunto de medidas que envolvem a privatização e o desmonte dos direitos sociais e trabalhistas, tendo por objetivo "[...] a pura e simples restauração das contradições próprias de um capitalismo 'selvagem' [...]” (COUTINHO apud CARAMURU, 2018a, p. 192), capaz de alimentar a insaciabilidade da finança que, insatisfeita com a capacidade objetiva de lucratividade a ser alçada mediante ativos econômicos, encontra a rentabilidade desejada através de apropriações crescentes de parcelas do fundo público por intermédio da dívida pública, a qual representa o "[...] pilar do poder das instituições que centralizam o capital portador de juros" (CHESNAIS, 2005, p. 44), implicando em fortes pressões fiscais aos Estados nacionais, para que estes se comprometam com os serviços da dívida e paralisem suas despesas públicas, implementando políticas de austeridade e ampliando as privatizações dos serviços públicos, com destaque para os sistemas de previdência, os quais também representam o pilar das políticas de sustentação e alimentação dos mercados financeiros. 
Caudatária da "cultura da crise" (MOTA, 2005), a previdência social tornou-se meta prioritária dos ajustes estruturais impostos aos países capitalistas, num contexto onde "[...] o fundo público de modo geral e o fundo público alocado na política social previdenciária, em particular, passou a funcionar como elemento basilar para as provisórias resoluções das crises". (GRANEMANN, 2012, p. 253). Assim, o debate sobre as mudanças no âmbito dos sistemas públicos de aposentadorias e pensões compõe o rol das grandes questões nacionais e provocam preocupação. Destaca-se que tais mudanças atuam no sentido de "[...] restringir e suprimir o potente vínculo de solidariedade social que os sistemas de aposentadorias geraram nas sociedades ocidentais". (LOBATO, COSTA \& RIZOTTO, 2019, p. $5)$.

Conforme aponta Boschetti (2012), as análises são unânimes em evidenciar que, até meados dos anos de 1990, as tendências das "reformas" nos sistemas de proteção social priorizavam a redução de direitos no âmbito dos sistemas públicos de aposentadorias, por meio, especialmente, do aumento da idade mínima para concessão dos benefícios, elevação do montante das contribuições sociais e redução dos valores dos benefícios. A autora destaca, entretanto, que desde os anos 2000, não contentados com as restrições provocadas até então, as contrarreformas impuseram sucessivos ataques estruturais aos sistemas de proteção social no intuito de reforçar a acumulação do capital, apostando, sobretudo, na introdução ou reforço dos sistemas privados e/ou complementares de aposentadoria, financiados por capitalização que, na verdade, nada mais são do que uma mediação para realização do capital portador de juros. (GRANEMANN, 2006).

Há, portanto, uma intrínseca correlação entre a deterioração definitiva da provisão pública e os interesses das finanças e, mais especificamente, dos fundos de previdência privada. Para compreensão da lógica que subjaz esse processo há, primeiramente, que se considerar o potencial econômico que a previdência social alcançou nos marcos da sociedade regida pela propriedade privada. Conforme nos explica Granemann (2012), a política de previdência social, mais do que as demais políticas sociais, tem a capacidade de acumular substantivo volume de recursos monetários, advindo das contribuições do capital e do trabalho, visto que, em quase todo mundo, essa política social é ativada mediante contribuição prévia, cabendo ao Estado o recolhimento e posterior distribuição entre os que tenham direito à previdência. Ora, em tempos de ferrenha disputa pelos recursos do fundo 
público, o superávit dessa política, comumente dita em crise, faz-se elemento central para formação da riqueza social que remunera títulos públicos de propriedade do capitalbancário financeiro e dos investidores institucionais ${ }^{2}$, dentre estes, fundos de pensão e entidades abertas de previdência privada, de tal forma que, o desmantelamento dos sistemas públicos tornou-se exigência para que a exuberância de recursos acumulados por essa política não escapem dos circuitos de valorização das finanças. (BUENO \& MUSTAFA, 2019).

A segunda questão importante a se destacar é que "[...] a utilização dos recursos da previdência dos trabalhadores, não se restringe apenas à "formação de poupança interna". (GRANEMANN, 2012, p, 253). O rebaixamento dos valores dos benefícios previdenciários, somado às condicionalidades cada vez mais restritivas de acesso ao direito à aposentadoria, viabilizou a expansão de um mercado previdenciário, "[...] que funciona diretamente como espaço de inversão de capitais em busca de valorização" (2012, p. 254), deslocando receitas significativas advindas da renda da classe média e alta, que poderiam estar sendo canalizadas para o sistema público, de maneira a fomentar a redistribuição e fortalecer o equilíbrio financeiro do sistema para os circuitos de valorização das finanças. (LAVINAS \& ARAÚJO, 2017).

Assim, em outros termos, as contrarreformas restritivas de direitos no âmbito dos sistemas públicos de aposentadoria são exigências do grande capital, e do seu Estado, para criar as condições necessárias para orientar os trabalhadores na aquisição da mercadoria previdência privada. Estudos recentes evidenciam o crescimento intenso dos fundos de previdência nos países da Organização para a Cooperação e Desenvolvimento Econômico (OCDE) e nos Estados Unidos (GENTIL, 2019). No caso do Brasil, a evolução das carteiras de investimentos dos fundos abertos e fechados de previdência complementar também demonstram os montantes de recursos que vêm sendo destinados às formas privadas de planos previdenciários, registrando, no período de 2010 a 2017, um aumento de $243 \%$ dos seus ativos na modalidade aberta, e 49\% na modalidade fechada. (ROZENDO, 2018).

\footnotetext{
${ }^{2}$ Investidor Institucional: "Mais importante participante dos mercados financeiros e de capitais, em face de sua imensa massa de manobra, que são os recursos captados junto a seus públicos. São os profissionais da aplicação de recursos de terceiros, entidades que merecem atenção especial da autoridade monetária, quando se trata de manter a liquidez dos mercados financeiros. Os principais investidores institucionais são: a) fundos de pensão e entidades de 'previdência privada'; b) montepios; c) fundações de seguridade social; d) fundos de investimento; e) companhias de seguros e capitalização; f) companhia de investimentos". (RUDGE, apud GRANEMANN, 2006, p. 34).
} 
É importante destacar, ainda, que, segundo estudos de Granemann (2006) e Caramuru (2018b), apesar das entidades de previdência privada mobilizarem valores anuais maiores do que os mobilizados pela previdência pública, essas estão longe de serem as formas mais abrangentes de aposentadoria, visto que não alcançam a maioria dos trabalhadores; os valores não ultrapassam significativamente os valores oferecidos pelos programas de previdência pública; o número de benefícios oferecidos é mais restrito; e, enquanto investidores institucionais, não garantem segurança à aposentadoria do trabalhador, uma vez que seus recursos tem por vocação a acumulação capitalista, desempenhando papel central nos mercados de capitais e, especialmente, nas especulações financeiras (BUENO \& MUSTAFA, 2019). Exemplo disso é que, a partir da década de 1980, observou-se um movimento de substituição dos planos de benefício definido por planos de contribuição definida, considerando que cada plano "[...] imputa a quem caberá o risco das aplicações financeiras ditas previdenciárias" (GRANEMANN, 2006, p. 32): na primeira modalidade, os riscos são divididos entre capital e trabalho, e no caso dos planos por contribuição definida "[...] se os investimentos lograram sucesso haverá uma substantiva aposentadoria; mas, na ocorrência do contrário, isto é, se a gestão de seus 'ativos' não tiver obtido sucesso, o trabalhador poderá não ter aposentadoria". (GRANEMANN, 2006, p. 32).

Por fim, ressalta-se que, apesar da ampla vertente da teoria econômica justificar o fortalecimento dos sistemas de capitalização como estratégia ao crescimento econômico e investimento produtivo, mediante estímulo à poupança individual, o trabalho realizado por Altipar-makov e Nedeljkovic (apud LAVINAS \& ARAÚJO, 2017), abarcando América Latina e Leste Europeu, indica, com segurança, que não há nenhuma associação entre privatização da previdência social e rápido crescimento econômico, concluindo, no geral, que o processo de privatização das aposentadorias dos países que passaram por reformas não produziu efeitos nas taxas de crescimento, notadamente se comparados à evolução do crescimento daqueles que não as adotaram.

Esse cenário evidencia, portanto, que os sistemas de previdência vêm sendo alvos prioritários do capital, que por meio do seu Estado, implementa constantes contrarreformas, as quais afetam diretamente o potencial e a qualidade desta política pública, conforme elucidaremos a seguir no caso brasileiro. 


\title{
A orientação político-econômica do atual antigoverno do Brasil e a contrarreforma da previdência social aprovada em outubro de 2019
}

A partir do golpe que se instaura no Brasil, em 2016, o qual retira a presidenta Dilma Rousseff do poder, um projeto de neoliberalismo de tipo mais radical vai ser implementado no Brasil, primeiro, pelas mãos de Michel Temer:

\begin{abstract}
Este projeto começa a ser levado a cabo pelo político corrupto Michel Temer, sobretudo quando aprova, em seu rápido e desastroso governo, a Emenda Constitucional (EC) no 95, a qual institui um novo regime fiscal no Brasil, congelando por 20 anos os gastos primários, o que em miúdos coloca o fundo público a favor dos rentistas compradores dos títulos da dívida pública, e ao mesmo tempo espolia a classe trabalhadora uma vez que desfinancia políticas sociais, as quais nas últimas décadas possibilitaram avanços no índice de pobreza e desigualdade social (medida pela renda do trabalho), além de aprovar contrarreformas que subtraem direitos dos trabalhadores, como a contrarreforma trabalhista (MUSTAFA et al, 2019, p. 3).
\end{abstract}

A EC 95/2016 atesta a perversidade deste neoliberalismo radical, que espolia ainda mais o fundo público, diga-se o orçamento social, sem prejuízo, ao contrário com ganhos exorbitantes, para o mundo das finanças, acompanhando o que explicamos no item anterior. Para comprovar, no ano de 2019, foi despendido R\$1,038 trilhão (AUDITORIA, 2020) com pagamento de juros e amortizações da dívida pública, em que pese a situação social caótica vivida pelo país no mesmo ano, com milhões de desempregados e subempregados.

Assim, este neoliberalismo radicalizado ou ultraneoliberalismo se refere àquilo que a economista Leda Paulani (2016, p. 75) chama de "agenda puro sangue do neoliberalismo", ou seja, abertura comercial, sem nenhum compromisso com o Mercado Comum do Sul (MERCOSUL); ampliação das privatizações (mesmo de setores estratégicos para o país), livre câmbio, ainda que isso signifique, segundo Paulani (2016) em danos à indústria nacional. Implica também em flexibilização de direitos trabalhistas, e redução drástica do orçamento social (EC 95/2016), desta maneira, dos direitos sociais garantidos na Constituição Federal (CF) de 1988.

Seguindo o mantra dos cortes sociais este governo também apresentou a PEC 287/2016, proposta de contrarreforma da previdência social com mudanças "[...] consideradas as mais radicais, rompendo com os princípios de solidariedade social e de proteção aos trabalhadores e moldando-a como um bem de mercado". (BUENO \& 
MUSTAFA, 2019, p. 11). Entretanto, a mesma não caminhou neste governo, mas uma nova proposta eclodiu assim que Bolsonaro assumiu, em janeiro de 2019, por via da PEC 06/2019.

Este antigoverno de Bolsonaro além de dar seguimento à orientação radical do neoliberalismo, com profunda contrarreforma do Estado, que inclui contrarreforma da previdência social, privatizações, desresponsabilidade do Estado em questões fundamentais como a ambiental, por exemplo, vide as contra-ações no que se refere ao desmatamento da Amazônia e ao derramamento de óleo na costa brasileira, ademais apresenta-se como um governo altamente conservador - conservadorismo expresso nas suas declarações e comportamentos homofóbicos, misóginos, Igbtfóbicos, racistas, perseguição à indígenas e quilombolas.

Neste artigo, em específico neste item, nos deteremos na análise da contrarreforma da previdência social apresentada por este governo (PEC 06/2019), e já aprovada pelo congresso nacional e senado em outubro deste mesmo ano. Esta PEC passa a ser a EC 103/2019 promulgada em 12 de novembro de 2019.

Novamente o velho argumento de déficit na previdência social é mobilizado e acaba por convencer, com auxílio midiático, a maior parte da população de que realmente se fazia necessário uma nova "reforma" da previdência social. Ocorre que, se analisarmos as fontes de financiamento da previdência social - RGPS -, como política de seguridade social, veremos que esta é superavitária.

Considerando as principais fontes de financiamento deste sistema, como a Contribuição para o Financiamento da Seguridade Social (COFINS) e a Contribuição Social sobre o Lucro Líquido (CSLL), em 2018, a previdência social não é deficitária, pois sua receita perfaz um valor de $R \$ 721,7$ bilhões, enquanto suas despesas são na ordem de $R \$ 589,74$ bilhões. Assim, temos um saldo positivo no valor de $\mathrm{R} \$ 131,96$ bilhões. (ARRAIS \& VIANA, 2019). É importante observar que o ano de 2018 foi marcado pelo crescimento de desemprego, o qual seguiu alto no ano de 2019 , encerrando o trimestre de julho a setembro de 2019, segundo a Agência IBGE (2019), em 11,8\% e a taxa de subutilização no mesmo trimestre em $24 \%$, o equivalente a 27,5 milhões de pessoas. $E$ também por altíssimos níveis de trabalho informal, 11,8 milhões de pessoas no setor privado, número recorde na série histórica, tendo crescido 2,9\% (ou mais 338 mil pessoas) em relação ao trimestre anterior de 2019, e 3,4\%, mais 384 mil pessoas, em comparação a igual trimestre de 2018. 
Desta maneira, foi um ano em que as arrecadações tenderam a diminuir. Mas, ainda assim, isso não comprometeu o saldo positivo da previdência social.

Agora, se se retira a COFINS e a CSLL, e se inclui outras despesas como o Beneficio de prestação Continuada (BPC), despesas com o Regime Próprio de Previdência Social (RPPS) da União para os civis e militares, aí sim, se detectará um déficit, argumento este adotado pelo atual governo para afirmar o mesmo.

Também a justificativa de que há déficit nos RPPSs é uma falácia. Segundo Arrais e Viana (2019), há no Brasil 2.091 municípios com Regimes Próprios de Previdência Social, e desse contingente, 1.616 apresentaram superávit, em 2017. Apenas 475 municípios apresentaram RPPS deficitário.

Outro argumento muito utilizado para justificar as "reformas" da previdência social é a de que há muitos privilegiados sendo cobertos por este sistema. Nesse sentido, cabe-nos evidenciar, por meio de dados concretos, que esse argumento também se configura numa falácia. A média dos benefícios previdenciários, em dezembro de 2018, segundo dados do próprio Instituto Nacional do Seguro Social (INSS), das aposentadorias urbanas foi de $\mathrm{R} \$ 1.487,37$ e das aposentadorias rurais de $\mathrm{R} \$ 953,43$. (DIEESE, 2019). Ou seja, no caso das aposentadorias urbanas um pouco acima de 1 (um) salário mínimo, por suposto que esta média varia de região pra região; mas $43 \%$ do total de aposentados urbanos recebem até 2 (dois) salários mínimos e 41\% destes recebem entre 2 (dois) e 4 (quatro) salários mínimos. No caso das aposentadorias rurais, quase que a sua totalidade é de 1 salário mínimo. Pois bem, com esta média dos valores das aposentadorias, dá para dizer que o Regime Geral de Previdência Social está atendendo a privilégios?

Estes dados comprovam que a previdência social (RGPS) atende aos trabalhadores brasileiros, que na sua maioria são pobres, vide o valor dos benefícios que auferem mensalmente. E ainda que estas rendas sejam baixas, elas impactam na vida destes trabalhadores e de suas famílias, na redução da pobreza e miséria no país, e também para a economia, pois os benefícios previdenciários convertem-se em consumo, desta maneira, impactando no fomento ao mercado.

Porém, o capitalismo financeirizado, de hoje, como atesta Meszáros (1989), é destrutivo, ou seja, não se importa com a satisfação das necessidades humanas e tampouco com a economia local, este capital quer este recurso disponível no fundo público para satisfazer unicamente sua fome voraz por mais capital, como já demonstramos neste artigo. 
Daí a proposta do atual governo e seu ministro da economia, de capitalização, que nada mais é do que uma forma de capitalizar sobremaneira o capital financeiro, atuando na sua brutal reprodução e acumulação.

Esta é a real justificativa, não dita, para enxugar os gastos públicos com direitos sociais, como o previdenciário, por exemplo. E a ciência precisa evidenciar e, desta forma, denunciar estes dados ontológicos.

Mas, como os ventos que sopram atualmente são os do neoliberalismo radicalizado e de um poder legislativo (congresso e senado) no qual grande parte dos políticos advogam por interesses daqueles que os financiaram e financiam, a EC 06/2019 é aprovada pelo Senado Federal $^{3}$ no dia 23 de outubro de 2019, não sem resistências e não sem modificações em relação à proposta original.

Uma vez aprovada a PEC e promulgada a EC 103/2019, passamos a evidenciar e analisar as principais mudanças, elucidando seus impactos para os trabalhadores.

A idade mínima para aposentadoria que passa a vigorar é de 62/65 anos, para mulher/homem, como norma geral do RGPS e do RPPS da União (há regras de transição), aumentando-se a idade mínima para as mulheres. Assim, se extinguiu a aposentadoria por tempo de contribuição no RGPS, que não exige idade mínima. Há algumas diferenciações de idades para distintas categorias profissionais, como para os professores (as) - 57/60 anos (mulher/homem) -, trabalhador rural e da economia familiar - 55/60 anos (mulher/homem) , não havendo alteração da regra atual; policial civil federal, de ambos os sexos - 55 anos; para os trabalhadores expostos a condições que prejudiquem a saúde - 55,58 ou 60 anos de idade, para tempo de exposição de 15, 20 ou 25 anos, respectivamente; servidor público federal exposto a condições prejudiciais à saúde - 60 anos; e pessoa com deficiência - não se estabeleceu idade mínima, mas está condicionada ao tempo de contribuição que varia de 20 a 33 anos, dependendo do sexo e da severidade da deficiência, ou com 55/60 anos (mulher/homem), cumpridos 15 anos de contribuição. (DIEESE, 2019). Em geral, elevaram-se as idades mínimas para aposentadoria de homens e mulheres, na especificidade destas últimas. Ressaltamos que a maioria das mulheres têm jornadas de trabalho duplas, triplas,

\footnotetext{
${ }^{3}$ A PEC 06/2019 foi aprovada em primeiro turno no Senado no início de outubro/19, com 56 votos favoráveis e 19 contrários; e no segundo turno, no dia 22 de outubro/2019, com 60 votos a favor e 19 contra. (AGÊNCIA SENADO, 2019a).
} 
ou seja, isto deveria justificar um olhar mais acurado para esta questão, no intuito de proteger às mulheres dupla/triplamente trabalhadoras; e, no caso de ambos os sexos, a elevação da idade mínima associada ao aumento do tempo mínimo de contribuição, dificultará o acesso ao benefício.

Vale destacar que foi importante a retirada da proposta de elevação automática das idades mínimas de aposentadoria condicionada ao aumento da expectativa de sobrevida da população, como apresentado na proposta original.

Quanto ao tempo mínimo de contribuição no RGPS foi mantido em 15 anos para os homens e mulheres que já estão no RGPS. Mas, para os futuros segurados homens, os que se registrarem após a promulgação da reforma, o tempo mínimo de contribuição passa de 15 para 20 anos, incluindo trabalhadores urbanos e rurais. (DIEESE, 2019).

\begin{abstract}
Tendo em vista o mercado de trabalho brasileiro, altamente rotativo e com empregos precarizados, a maioria dos trabalhadores, atualmente, não consegue contribuir com 15 anos (tempo mínimo estabelecido hoje), oxalá 20 anos; essa alteração excluirá de 70 a $80 \%$ da classe trabalhadora da proteção previdenciária, segundo Fagnani (2019). O que isso vai acarretar? Num aumento exorbitante de trabalhadores idosos empobrecidos e que, não tendo acesso aos benefícios previdenciários, vão buscar a sobrevivência na política de assistência social (política de seguridade social voltada para os trabalhadores pobres), e/ou na velha/nova filantropia. (BUENO \& MUSTAFA, 2019, p. 11-12).
\end{abstract}

Acerca das alíquotas de contribuição dos segurados, foi aprovada, de acordo com o texto original para o RGPS e RPPS da União, alíquota mínima de 7,5\%, havendo um decréscimo de $0,5 \%$, pois antes era $8 \%$, o que se considera positivo tendo em vista que se trata da alíquota que atinge os trabalhadores que auferem menor renda. Já a alíquota máxima sobe de $11 \%$ para $14 \%$, o que se configura num aumento significativo tratando-se também de trabalhadores que auferem uma renda um pouco acima da maioria (entre $\mathrm{R} \$$ $2.919,73$ a $\mathrm{R} \$ 5.839,45$ - teto), mas que não se tratam de super salários e tampouco de privilégios. Para benefícios que excedem o teto, as alíquotas são maiores, podendo chegar até $22 \%$.

Ainda falando de contribuições, o servidor aposentado ou pensionista do RPPS poderá vir a ter que contribuir sobre a parcela do benefício que exceda o salário mínimo. Nas regras atuais, somente aqueles cujos benefícios estejam acima do teto do RGPS, o fazem, condicionado ao déficit atuarial do respectivo regime. Esta mudança é muito preocupante do ponto de vista da garantia dos benefícios (aposentadoria e pensões), pois dá margem para futuras expropriações de aposentadorias e pensões, já muito rebaixadas pelo 
valor do salário mínimo, pela nova forma de cálculo dos benefícios, a qual exporemos logo em seguida neste artigo.

E ainda mais agravante é que se esta contribuição a mais, exposta no parágrafo acima, não for suficiente, serão permitidas contribuições extraordinárias no intuito de “[...] equacionar o déficit atuarial do regime, para os servidores ativos, os aposentados e os pensionistas do RPPSs da União (e dos estados e municípios)". (DIEESE, 2019, p. 9). Ou seja, não há garantia nenhuma de que a contribuição respeite as alíquotas definidas previamente.

Dentre tantas más notícias, a subida da alíquota da CSLL para os bancos de $15 \%$ para $20 \%$ é algo importante. Mas atenção, se os regimes de capitalização forem aprovados, estes $5 \%$ a mais desta contribuição para os bancos não tem impacto nenhum sobre seus lucros; e mais, há de se registrar que em 2017, houve um perdão da dívida para com a previdência social na ordem de aproximadamente $\mathrm{R} \$ 30$ bilhões dos bancos Bradesco, Itaú e Santander. (WACLAWOVSKY, 2018).

No que concerne ao cálculo do valor das aposentadorias do RGPS e do RPPS da União, este será feito a partir de $60 \%$ da média dos salários de contribuição, mais $2 \%$ para cada ano de contribuição que exceda a 15 anos, para a mulher (RGPS), e para a aposentadoria especial com 15 anos em condição prejudicial à saúde, ou que exceda a 20 anos para os homens do RGPS e para servidores e servidoras da União. Terá valor de 100\% da média a aposentadoria por incapacidade decorrente de acidente de trabalho, doença de trabalho e doença profissional ${ }^{4}$. A aposentadoria decorrente de acidente ou doença grave terá valor calculado pela regra geral, e não mais de $91 \%$ da média, como era anteriormente. (DIEESE, 2019).

Esta alteração ocasionará diminuição ${ }^{5}$ dos valores dos benefícios, traduzindo-se em empobrecimento da já pobre classe trabalhadora no Brasil. Hoje, $43 \%$ dos beneficiários (urbanos) da previdência social recebem de 1 a 2 salários mínimos, e quase a integralidade dos trabalhadores rurais recebem apenas 1 salário mínimo, como já indicamos neste artigo.

\footnotetext{
4 "Doença ocupacional ou profissional decorre do exercício de uma atividade específica, enquanto a doença do trabalho é resultante das condições em que o trabalho é executado". (DIEESE, 2019, p. 5).

${ }^{5}$ O DIEESE (2019, p. 5) dá um exemplo que ilustra esta diminuição: "[...] se um trabalhador contribuir por 20 anos, com média de $\mathrm{R} \$ 5.000,00$ mensais, terá aposentadoria de $\mathrm{R} \$ 3.000,00$ (=60\% de $\mathrm{R} \$ 5.000,00)$. Se ele contribuir por mais 10 anos sobre $R \$ 1.000,00$ mensais, em média, a aposentadoria seria de apenas $R \$$ $2.933,33$, pois corresponderia a $80 \%(60 \%+10 \times 2 \%)$ da média salarial total de $R \$ 3.666,66\{=(20 \times 5.000+10$ x 1.000) / 30\}".
} 
Assim, fica a pergunta, por que espoliar ainda mais os benefícios da classe trabalhadora já tão espoliada neste país?

Entretanto, de acordo com a proposta original desta PEC, poderia ainda ser pior, se houvesse desvinculação entre o piso das aposentadorias e o salário mínimo, e isso foi revertido, ou seja, mantém-se a vinculação. E também se manteve a obrigação de reajustes dos benefícios previdenciários.

Em relação ao valor das pensões, foi aprovada a fórmula (de acordo com a proposta versão original) de cotas familiares de $50 \%$, mais $10 \%$ por dependente, não reversíveis, aplicadas sobre o valor da aposentadoria que o segurado recebia ou receberia se aposentasse por invalidez na data do óbito. Seguindo esta forma de cálculo, o valor da pensão será menor do que o pago nas regras anteriores. Apenas para os casos de dependente inválido ou com deficiência intelectual, mental ou grave, a pensão será de 100\% da aposentadoria, não podendo ultrapassar o teto máximo do RGPS. (DIEESE, 2019).

Para as pensões de dependentes de policial vinculado ao RPPS da União, o Senado manteve a pensão vitalícia e de valor igual à última remuneração em caso de falecimento decorrente de agressão no exercício da função ou em decorrência dela. Essa regra também será aplicada aos RPPSs de estados e municípios, caso estes adotem a PEC 06/2019. (DIEESE, 2019).

Outro elemento é que não se poderá acumular benefícios: foi vedado recebimento de duas aposentadorias ou de duas pensões no mesmo regime, e mantidas as restrições ao recebimento de dois ou mais benefícios de regimes diferentes, ressalvados alguns casos específicos (como o de "dois cargos" nas áreas de saúde e educação de RPPSs). Quando for possível a acumulação, o segurado receberá integralmente o beneficio de maior valor e parcialmente os demais, de forma inversamente proporcional ao valor. (DIEESE, 2019).

Ainda foram aprovadas algumas regras para ordenar o RPPS, estas não serão destacadas aqui neste artigo, mas é fundamental o estudo crítico das mesmas uma vez que propõem mudanças substanciais para os servidores públicos.

A contrarreforma aprovada ainda propõe mudanças no orçamento da seguridade social. Primeiramente, mantém a separação das contas de receitas e de despesas da Saúde, da Previdência Social e da Assistência Social, políticas sociais que compõem a seguridade social brasileira, rompendo assim com o conceito de seguridade social e reforçando a compartimentalização de cada uma destas políticas; em seguida estabelece o fim da 
Desvinculação das Receitas da União (DRU) para receitas da seguridade; e o repasse de $28 \%$ da arrecadação do Programa de Integração Social/Programa de Formação do Patrimônio do Servidor Publico (PIS/Pasep) ao Banco Nacional de Desenvolvimento Social ${ }^{6}$ (BNDS). (DIEESE, 2019). No tocante ao fim da incidência da DRU na receita da seguridade social, destaca-se esta como fundamental, uma vez que a DRU vinha subtraindo largos recursos do sistema de seguridade social: $\mathrm{R} \$$ 99,4 bilhões e $\mathrm{R} \$ 113$ bilhões destas receitas, nos anos de 2016 e de 2017, respectivamente (ANFIP, 2018), sem mencionar os anos anteriores, pois a DRU vigora desde a década de 1990 sob outros nomes, e a partir de 2000 com este nome, usurpando o orçamento da seguridade social e, portanto, o fundo público, no que concerne a garantia de direitos tão elementares quanto à saúde, previdência e assistência social. Lembrando que em 2016, a EC 93 ampliava de 20\% para 30\% o percentual que poderia ser desvinculado dos tributos, e alterava os tributos nos quais a mesma poderia incidir. Então, acabar com a incidência da DRU nas receitas da seguridade social é de extrema importância para a garantia dos recursos próprios, de acordo com a CF de 1988, no que se refere ao financiamento da seguridade social. Vale destacar que a necessidade do fim da DRU foi apontada pelo Relatório da Comissão Parlamentar de Inquérito da Previdência Social de 2017 (CPIPREV, 2017), bem como vinha sendo apontado veementemente pela Associação Nacional dos Auditores Fiscais da Receita Federal do Brasil (ANFIP) e estudiosos da Previdência e seguridade social.

Se por um lado o antigoverno apresenta esta proposta, por outro queria a inclusão do RPPS da União na seguridade social. Isso implicaria em que os RPPSs dos civis, mas sobretudo dos militares (o qual é deficitário), engoliria os recursos que não são de uma categoria profissional, mas de toda população brasileira, uma vez que a seguridade social extrapola a previdência social, e tem como princípio a universalidade.

Ainda, a depender de lei complementar, a contrarreforma ampliou a possibilidade de oferta de benefícios não programados ${ }^{7}$ pelo setor privado, concorrencialmente à previdência pública, o que hoje se limita ao seguro acidente de trabalho. (DIEESE, 2019).

\footnotetext{
6 "Considerando que a arrecadação do PIS/Pasep deixa de sofrer a incidência da DRU, de 30\%, o percentual de destinação de $28 \%$ mantém a situação atual de repasse de $40 \%$ daquela arrecadação”. (DIEESE, 2019, p. 11)

7 "Benefícios não programados são aqueles cuja concessão depende de eventos não previsíveis, como morte, invalidez, doença, acidente e reclusão.” (DIEESE, 2019, p.11).
} 
É importante destacar que a proposta de capitalização, apresentada pela proposta original, foi retirada de pauta pelo congresso nacional após pressão social, mas o antigoverno diz que voltará a propor o regime de capitalização, lembrando que o mesmo foi efetuado no Chile durante a ditadura de Pinochet e, segundo o diagnóstico do economista chileno Andras Uthoff, em entrevista à Carta Capital, dia 19 de março de 2019, este modelo:

Não deu certo: $79 \%$ das pensões financiadas pelo sistema, mesmo após os subsídios estatais, estão abaixo do salário mínimo chileno (cerca de 1810 reais). E $44 \%$ dos aposentados vive abaixo da linha da pobreza, ganhando menos de 600 reais por mês. Isso não foi resolvido no Chile e não será resolvido no Brasil com capitalização individual. (UTHOFF, 2019, on-line).

Mesmo com estes dados o antigoverno e seu ministro da economia continuam insistindo nesta proposta sob o argumento de que com a reforma da previdência o país voltará a crescer e atrair novos investimentos.

Outra promessa furada, diz Uthoff, é que os investimentos da Previdência privada impulsionariam a economia chilena. Do fundo de 200 bilhões de dólares em recursos poupados pelos trabalhadores, quase 3/4 do PIB do país, cerca de $40 \%$ estão investidos no exterior. (UTHOFF, 2019, on-line).

Desta maneira, recolocamos a pergunta: "[...] a qual capital o sistema de capitalização beneficia em países de capitalismo periférico e subordinados?" (BUENO; MUSTAFA, 2019, p. 13).

Um ponto fundamental, também não aprovado, foi a alteração que se propunha no BPC, benefício da política de assistência social que atende a idosos e pessoas com deficiência miseráveis do país, num valor de 1 salário mínimo. Este valor permanece, ainda que se queria rebaixá-lo para $\mathrm{R} \$ 400,00$, e sem definição de regras de reajuste.

Agora, ainda é preciso ficarmos alertas porque tramita-se a PEC 133, chamada de Paralela, a qual traz, dentre outros, a aplicação das regras da contrarreforma aos servidores de estados, do Distrito Federal (DF) e dos municípios. Segundo o DIEESE (2019, p. 2): "Sob pressão para aprovar logo a reforma, o Senado evitou efetuar mudanças que fariam a PEC voltar para a Câmara e deixou para tratar dos pontos divergentes em nova PEC, de número $133^{\prime \prime}$.

E o Senado já concluiu no último dia 19 de novembro a votação da PEC 133, a qual altera pontos da reforma da previdência (EC 103/2019). Assim, a PEC Paralela já seguiu para 
votação na Câmara dos Deputados. O texto aprovado diz que todos os entes federativos (estados, Distrito Federal e municípios) podem adotar integralmente as mesmas regras aplicáveis ao RPPS da União por meio de lei ordinária, a qual precisará de aprovação em suas assembleias legislativas, câmaras de vereadores e, no caso do DF, em sua câmara distrital. E mais, em caso de os municípios não aprovarem suas regras próprias terão que aderir automaticamente ao regime da União, caso o sistema tenha sido adotado pelo estado do qual fazem parte. $\mathrm{O}$ texto abre a possibilidade de que estados e municípios revejam a decisão de aderir à reforma da União por projeto de lei. (AGÊNCIA SENADO, 2019b).

Há várias outras proposições na PEC Paralela, mas não há espaço para tratarmos disso neste artigo. O que já, de antemão, destacamos é que precisamos estar em alerta, pois a contrarreforma da previdência ainda não foi concluída e outras regressões podem vir a ocorrer se não estivermos vigilantes.

Neste sentido, representantes de nove centrais sindicais lançaram no último dia 12 de novembro a "campanha Permanente em Defesa da Previdência e Seguridade Social". E já anunciaram mobilizações para os dias 22 e 26 de novembro deste ano (2019).

\section{Algumas conclusões:}

Para dar início à parte conclusiva deste ensaio, a primeira ideia que queremos reafirmar, com o auxílio de um grande pensador marxista, é que: “O Estado capitalista não foi projetado para transformações sociais de cunho emancipatório; ele foi moldado para sistematicamente apoiar a dominação do capitalismo [...]". (WRIGHT, 2019, p. 145).

E isso se dá de forma muito contundente, nesta fase de neoliberalismo radicalizado no Brasil, sem restrições, vide a EC 95/2016, que coloca os direitos sociais na UTI, previamente à morte dos mesmos. Vide as privatizações em curso, as quais tiram do controle público setores estratégicos para o desenvolvimento autônomo do país. E, vide a EC 103/2019 - da contrarreforma da previdência social, a qual analisamos nestes escritos.

Assim, o Estado capitalista brasileiro, nestes tempos, tem cumprido fielmente o seu papel de defesa do capital, especialmente do capital financeiro, conforme demonstramos no artigo, e isso implica/ou na apresentação e aprovação da contrarreforma da previdência social, para possibilitar um desfinanciamento desta política social e, assim, a ampliação da espoliação do fundo público pelo capital portador de juros. 
Esta contrarreforma altera o direito previdenciário brasileiro, acarretando em dificuldades para a classe trabalhadora, no sentido de conseguir acessar os benefícios previdenciários, sendo o principal deles a aposentadoria. Elucidamos que a maior parte das aposentadorias, hoje, pagas pelo RGPS não ultrapassa dois salários mínimos para os trabalhadores urbanos, e um salário mínimo para o trabalhador rural. Assim, é evidente que a maioria dos segurados deste regime é constituída de trabalhadores empobrecidos pelo processo de trabalho e pela falta de direitos inerentes ao mesmo. Com a EC 103/2019 este acesso será dificultado, pois os trabalhadores terão um aumento no tempo mínimo de contribuição e aumento da idade mínima para requererem este benefício, para além do valor auferido que diminuirá significativamente como ilustramos aqui neste ensaio. Ademais, podem ser exigidas contribuições extras, conforme mostramos, e há a possibilidade de que os benefícios não programados, há depender de lei complementar, sejam destinados ao setor privado.

Destacamos a relevância da retirada da proposta de capitalização do sistema previdenciário, derrubado no Congresso e no Senado por pressão popular, entretanto alertamos para o fato de que a mesma pode vir a ser apresentada novamente. O mesmo alerta deve-se ter no que se refere à PEC Paralela que acaba de ser enviada à Câmara dos Deputados.

Ainda para concluir é preciso atenção para ver se, de fato, a DRU deixará de incidir sobre as receitas da seguridade social, tal como posto na EC 103/2019, e medir este impacto para esta política social e as demais que compõem o sistema de seguridade social.

Para finalizar, o tempo presente nos coloca a exigência de pesquisas acuradas acerca do papel do Estado, do financiamento dos direitos sociais, das tendências destes direitos, a partir de um olhar amplo que capture as relações que se estabelecem entre a sociedade capitalista madura, o Estado que se constitui nessas condições sócio históricas, as classes sociais, as lutas sociais objetivadas nesse cenário, para que dentro dessa complexidade, possamos elucidar os desafios postos e os caminhos que podemos trilhar na superação dos mesmos.

\section{Referências}

AGÊNCIA IBGE. PNAD Contínua: taxa de desocupação é de $11,8 \%$ e taxa de subutilização é $24,0 \%$ no trimestre encerrado em setembro de 2019. 31 de out. 2019. Disponível em: 
$<$ https://agenciadenoticias.ibge.gov.br/agencia-sala-de-imprensa/2013-agencia-denoticias/releases/25814-pnad-continua-taxa-de-desocupacao-e-de-11-8-e-taxa-desubutilizacao-e-24-0-no-trimestre-encerrado-em-setembro-de-2019>. Acesso em: 18 de nov. de 2019.

AGÊNCIA Senado. Aprovado o texto-base da reforma da Previdência; Senado vota últimos destaques nesta quarta. 22 de out. 2019a. Disponível em: <https://www12.senado.leg.br/noticias/materias/2019/10/22/aprovado-o-texto-base-dareforma-da-previdencia-senado-vota-ultimos-destaques-nesta-quarta>. Acesso em: 24 de out. 2019.

Aprovada em dois turnos, PEC Paralela da Previdência segue para a Câmara. 19 de nov. 2019b. de Disponível em: <https://www12.senado.leg.br/noticias/materias/2019/11/19/aprovada-em-dois-turnospec-paralela-da-previdencia-segue-para-a-camara>. Acesso em: 20 de nov. de 2019.

Associação Nacional dos Auditores Fiscais da Receita Federal do Brasil. Analise Seguridade Social em 2017. Brasília (DF): ANFIP, 2018. Disponível em: <https://www.anfip.org.br/wpcontent/uploads/2018/12/Livros_28_11_2018_14_51_18.pdf>. Acesso em: 10 de março de 2019.

AUDITORIA Cidadã da Dívida. Brasília (DF): 2020. Disponível em: <https://auditoriacidada.org.br/wp-content/uploads/2020/02/Orc\%CC\%A7amento-2019versao-final.pdf $>$. Acesso em: abr. de 2020.

ARRAIS, Tadeu Alencar; VIANA, Juheina Lacerda. Pequeno atlas da tragédia previdenciária brasileira [recurso eletrônico], Goiânia: IESA: Gráfica / UFG, 2019.

BEHRING, Elaine. Brasil em contra-reforma: desestruturação do Estado e perda de direitos. São Paulo: Cortez, 2003.

BUENO, Bruna; MUSTAFA, Patrícia Soraya. Expansão do capital financeiro X retração da previdência social pública. In: III Congresso Internacional de Política Social e Serviço Social: desafios contemporâneos. Disponível em: <https://www.congressoservicosocialuel.com.br/trabalhos2019/assets/4604-231474-358202019-04-04.pdf>. Acesso em: 10 de nov. de 2019.

BOSCHETTI, Ivanete. A insidiosa corrosão dos sistemas de proteção social europeus. Serviço Social \& Sociedade, São Paulo, n. 112, 2012, p. 754-803.

BRAGA, José Carlos de Souza. Financeirização global: o padrão sistêmico de riqueza do capitalismo contemporâneo. In: TAVARES, Maria da Conceição; FIORI, José Luís (Org.) Poder e dinheiro: economia política da globalização. Petrópolis: Vozes, 1997. p. 195-242.

BRASIL. Constituição (1988). Emenda Constitucional no 95, de 15 de dez. de 2016. Brasília (DF): 2016. Disponível em: < http://www.planalto.gov.br/ccivil_03/Constituicao/Emendas/Emc/emc95.htm>. Acesso em: nov. de 2019. 


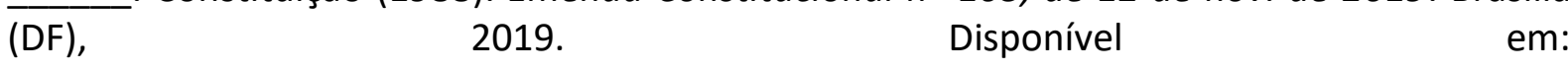
. Constituição (1988). Emenda Constitucional no 103, de 12 de nov. de 2019. Brasília <http://www.planalto.gov.br/ccivil_03/constituicao/emendas/emc/emc103.htm>. Acesso em: nov. de 2019.

BRUNO, Miguel; CAFFE, Ricardo. Estado e financeirização no Brasil: interdependências macroeconômicas e limites estruturais ao desenvolvimento. Economia \& Sociedade, Campinas, v. 26, 2017, p. 1025-1062.

CARAMURU, Thais Soares. Contrarreforma da Previdência Social sob a égide do capital portador de juros: uma ofensiva a serviço da "previdência privada". 2018a. Dissertação (Mestrado em Política Social) - Universidade de Brasília, Brasília.

. Previdência Social versus Fundos de Pensão: uma breve crítica marxista. In: Anais do $6^{\circ}$ Encontro Internacional de Política Social e $13^{\circ}$ Nacional de Política Social, Vitória (ES), v.1, n.1, 2018b, p. 1-16.

CHESNAIS, François. O capital portador de juros: acumulação, internacionalização, efeitos econômicos e políticos. In: CHESNAIS, François (Org.). A finança mundializada: raízes sociais e políticas, configurações, consequências. São Paulo: Boitempo, p. 35-69, 2005.

2015, p. 07-28.

Mundialização: o capital financeiro no comando. Revista Outubro, n. 02, vol. 05,

Comissão Parlamentar de Inquérito do Senado Federal destinada a investigar a contabilidade da previdência social (CPIPREV). Relatório Final. Brasília (DF): 2017. Disponível em: $<$ http://legis.senado.leg.br/sdleg-getter/documento/download/c20f0635-1112-4636-bc0c49a2ca4b919a>. Acesso em: nov. de 2019.

Departamento Intersindical de Estatística e Estudos Socioeconômicos (DIEESE). PEC 6/2019: como ficou a Previdência depois da aprovação da reforma no Senado Federal. Nota Técnica, n. 214. Disponível em:

$<$ https://www.dieese.org.br/notatecnica/2019/notaTec214ReformaPrevidenciaAprovada.ht $\mathrm{ml}$. Acesso em: nov. de 2019.

DUMÉNIL, Gérad; LÉVY, Dominique. Neoliberalismo - Neo-imperialismo. Economia \& Sociedade, Campinas, v. 16, n. 1, p. 1-19, 2007.

GENTIL, Denise. Reforma da Previdência e Acumulação Financeira - a lógica da financeirização acelerada da política social no Brasil. Associação Keynesiana Brasileira. Dossiê Especial AKB, 2019.

GRANEMANN, Sara. Fundos de Pensão e a metamorfose do "salário em capital". In: SALVADOR, Evilásio et al. (Orgs.). Financeirização, Fundo Público e Política Social. São Paulo: Cortez, p. 243-260, 2012.

Para uma interpretação marxista da 'previdência privada'. 2006. Tese (Doutorado em Serviço Social) - Universidade Federal do Rio de Janeiro, Rio de Janeiro. 
HARVEY, David. O Neoliberalismo: História e Implicações. São Paulo: Loyola, 2012.

LAVINAS, Lena; ARAÚJO, Eliane de. Reforma da previdência e regime complementar. Revista de Economia Política, n. 3, vol. 37, 2017, p. 615-635.

.; ARAÚJO, Eliane de; BRUNO, Miguel. Brasil: vanguarda da financeirização entre os emergentes? Uma análise exploratória. Texto para Discussão, n.32, 2017. Instituto de Economia da Universidade Federal do Rio de Janeiro. Disponível em: http://www.ie.ufrj.br/images/pesquisa/publicacoes/discussao/2017/tdie0322017 lavinasaraujobruno.pdf. Acesso em: jun. de 2019.

LOBATO, Lenaura de Vasconcelos Costa; COSTA, Ana Maria; RIZZOTO, Maria Lucia Frizon. Reforma da previdência: o golpe fatal na seguridade social brasileira. Saúde em Debate, $\mathrm{n}$. 120, vol. 43, 2019, p. 5-14.

MASCARO, Alysson Leandro. Estado e Forma Política. São Paulo: Editora Boitempo, 2013. MÉSZÁROS, István. Produção destrutiva e Estado capitalista. São Paulo: Ensaio, 1989.

MOTA, Ana Elizabete. Cultura da crise e Seguridade Social: Um estudo sobre as tendências da previdência e da assistência social brasileira nos anos 80 e 90. São Paulo: Cortez, 2005.

MUSTAFA, Patrícia Soraya; et al. O Projeto Ultraneoliberal em curso e as consequências para a neófita seguridade social brasileira. In: 160 Congresso Brasileiro de Assistentes Sociais (CBAS). Brasília: CFESS, 2019, v.1.

NETTO, José Paulo. Crise do capital e consequências societárias. Serviço Social \& Sociedade, São Paulo, n. 111, p. 413-429, 2012.

PAULANI, Leda Maria. Uma ponte para o abismo. In: JINKINGS, I.; DORIA, K.; CLETO, M. (org.). Por que gritamos golpe? Para entender o impeachment e a crise política no Brasil. São Paulo: Boitempo, 2016. p. 69-76.

. Bolsonaro, o ultraliberalismo e a crise do capital. Margem Esquerda, São Paulo, Boitempo, n. 32, 2019, p. 48-56.

ROZENDO, Francisco Henrique da Costa. 'Previdência Privada' aberta: o futuro da classe trabalhadora nas mãos dos capitais? 2018. Tese. (Doutorado em Serviço Social) Universidade Federal do Rio de Janeiro, Rio de Janeiro.

UTHOFF, Andras. Capitalização transformou adultos de classe média em idosos pobres [19 de março, 2019]. Carta Capital. Entrevista concedida a Thais Reis de Oliveira.

WACLAWOVSKY, Luciana. Temer cancela 422 mil benefícios sociais da população mais vulnerável do país. Portal Cult, 17/04/2018. Disponível em: https://www.cut.org.br/noticias/temer-cancela-422-mil-beneficios-sociais-da-populacaomais-vulneravel-do-pais-2364. Acesso em: abr. de 2019. 
WRIGHT, Erik Olin. Como ser anti-capitalista no século XXI? Tradução: Fernando Cauduro Pureza. São Paulo: Boitempo, 2019. 